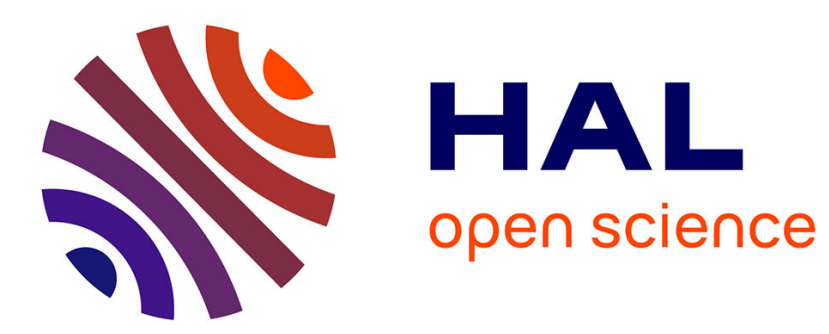

\title{
From the engraved tablet to the digital tablet, history of a fifteenth century music score
}

\author{
Ronan Gaugne, Françoise Labaune-Jean, Dominique Fontaine, Gaétan Le \\ Cloirec, Valérie Gouranton
}

\section{- To cite this version:}

Ronan Gaugne, Françoise Labaune-Jean, Dominique Fontaine, Gaétan Le Cloirec, Valérie Gouranton. From the engraved tablet to the digital tablet, history of a fifteenth century music score. Journal on Computing and Cultural Heritage, 2020, 13 (3), pp.1-18. 10.1145/3383782 . hal-02574884

\section{HAL Id: hal-02574884 \\ https://hal.science/hal-02574884}

Submitted on 14 May 2020

HAL is a multi-disciplinary open access archive for the deposit and dissemination of scientific research documents, whether they are published or not. The documents may come from teaching and research institutions in France or abroad, or from public or private research centers.
L'archive ouverte pluridisciplinaire HAL, est destinée au dépôt et à la diffusion de documents scientifiques de niveau recherche, publiés ou non, émanant des établissements d'enseignement et de recherche français ou étrangers, des laboratoires publics ou privés. 


\title{
From the engraved tablet to the digital tablet, history of a fifteenth century music score
}

\author{
RONAN GAUGNE, Univ Rennes, Inria, CNRS, IRISA, France \\ FRANÇOISE LABAUNE, Inrap, UMR 6566 CReAAH, France \\ DOMINIQUE FONTAINE, Independent professional singer, France \\ GAÉTAN LE CLOIREC, Inrap, UMR 6566 CReAAH, France \\ VALÉRIE GOURANTON, Univ Rennes, INSA Rennes, Inria, CNRS, IRISA, France
}

\begin{abstract}
This work illustrates the use of three different digitization techniques in order to study and valorize a 15th century engraved tablet discovered during a preventive archaeological excavation in the area of a former convent. The tablet is covered with engraved inscriptions on both sides, and includes a musical score. Digitization allowed for an advanced analysis of the inscriptions, and to generate a complete and precise 3D model of the artifact which was used to produce an interactive application deployed both on tactile tablets and website. The interactive application integrates a musical interpretation of the score that gives access to a testimony of intangible heritage. This interdisciplinary work gathered archaeologists, researchers from computer science and physics, and a professional musician.
\end{abstract}

CCS Concepts: • Applied computing $\rightarrow$ Arts and humanities; • Computing methodologies $\rightarrow$ Computer graphics.

Additional Key Words and Phrases: Digital Heritage, Archaeology, Tangible Heritage, Intangible Heritage, Music, Photogrammetry, RTI, ICT technologies in support of creating new cultural experiences or digital artifacts

ACM Reference Format:

Ronan Gaugne, Françoise Labaune, Dominique Fontaine, Gaétan Le Cloirec, and Valérie Gouranton. 2020. From the engraved tablet to the digital tablet, history of a fifteenth century music score. ACM f. Comput. Cult. Herit. 1, 1, Article 1 (January 2020), 19 pages. https://doi.org/10.1145/3383782

\section{INTRODUCTION}

At the crossroad of tangible and intangible heritage, we present the study of a fifteenth century engraved tablet that contains a musical score. This tablet was discovered during an important excavation in the center of the city of Rennes in Brittany, France [Le Cloirec 2014]. Considering the originality of this discovery, further investigations using digital technologies were proposed. In this context, digitization was used (i) to accompany the scientific study of the tablet, (ii) to preserve a fragile artifact, and (iii) to give easy access to this artifact through an interactive 3D application. The discovery of old musical scores is extremely valuable because they are few and they carry a representation of intangible heritage. Many ways of notating music existed throughout the human history [Lemberg 2016], and we can find some notable examples of engraved music such as the Mesopotamian Hurrian songs [West 1994], [Duchesne-Guillemin 1980], dating from 1400 BC, the Greek Seikilos

Authors' addresses: Ronan Gaugne, ronan.gaugne@irisa.fr, Univ Rennes, Inria, CNRS, IRISA, Rennes, France; Françoise Labaune, Inrap, UMR 6566 CReAAH, Rennes, France; Dominique Fontaine, Independent professional singer, France; Gaétan Le Cloirec, Inrap, UMR 6566 CReAAH , Rennes, France; Valérie Gouranton, valerie.gouranton@irisa.fr, Univ Rennes, INSA Rennes, Inria, CNRS, IRISA, Rennes, France. 
Column [Winnington-Ingram 1929], [Solomon 1986] which is approximately 2000 years old. While in the first example of the Hurrian songs, the music interpretation was not completely possible, the score of the Seikilos column is fully interpreted. We can find several musical interpretations of these scores; e.g., for the Hurrian songs the interpretation of by the Ensemble De Organographia [Ensemble De Organographia et al. 2006], and for the Seikilos Column an interpretation by Atrium Musicae de Madrid, from 1979 [Atrium Musicæ de Madrid and Paniagua 1979]. There are also other examples of interpreted engraved music. In 2017, Jones presented in [Jones 2017], the example of Renaissance knives with music engraved on their blades, and in 2012, an anonymous article in the Journal of Medieval Art and Architecture, [anonymous 2012], described a Renaissance score engraved on a church's exterior. In both church and knife engravings, the musical interpretations of the scores gave life to the intangible heritage handled by engraves on knives or building. During Renaissance, mensural musical notation was already well established, following the works in 13th and 14th centuries of Franco of Cologne (c. 1280) in his treatise Ars cantus mensurabilis ("The art of measured chant", [de Colonia et al. 1974]), and the French stylistic movement of the Ars nova [Reese 1959], [Brown and Stein 1999]. The number of lines in a musical stave can be four or five, and notes are represented by squares and diamonds as illustrated in this 15th century musical score kept in the French National Library (Fig. 1)

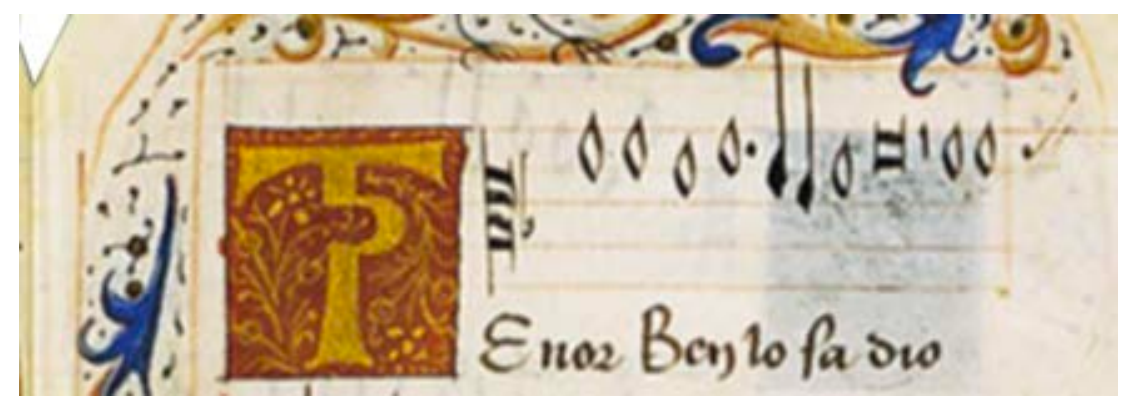

Fig. 1. Musical score "Chansonnier cordiforme", (fragment), Savoy, 15th century, BnF, Manuscrits, Rothschild $2973, f^{\circ} 1 v^{\circ}-2 r^{\circ}$ (c) Bibliothèque nationale de France

We first detail the discovery context of the tablet, then we present the analysis of the engraves on the tablet, the digitization steps of the tablet, and the development of the interactive application on a tactile tablet. We finish with a discussion of the contributions and open further perspectives.

\section{THE ORIGINAL ENGRAVED TABLET}

The original engraved tablet was found during preventive archaeological works at a convent in the center of the city of Rennes.

\subsection{The excavation of the convent of the Jacobins}

From December 2011 to June 2013, a major archaeological excavation was conducted in Rennes, Brittany, France, by Inrap (National Institute of Preventive Archaeological Research) before the development of the former convent of the Jacobins into a congress center (Fig. 2).

The convent of the Jacobins of Rennes was founded in 1368 and was particularly renowned between the fifteenth century (Fig. 3, left) and the seventeenth century (Fig. 3, right). Occupied by the army from the French Revolution, at the end of the eighteenth century, the building has been used as a military store for two centuries before being bought by Rennes-Métropole in 2002 . 


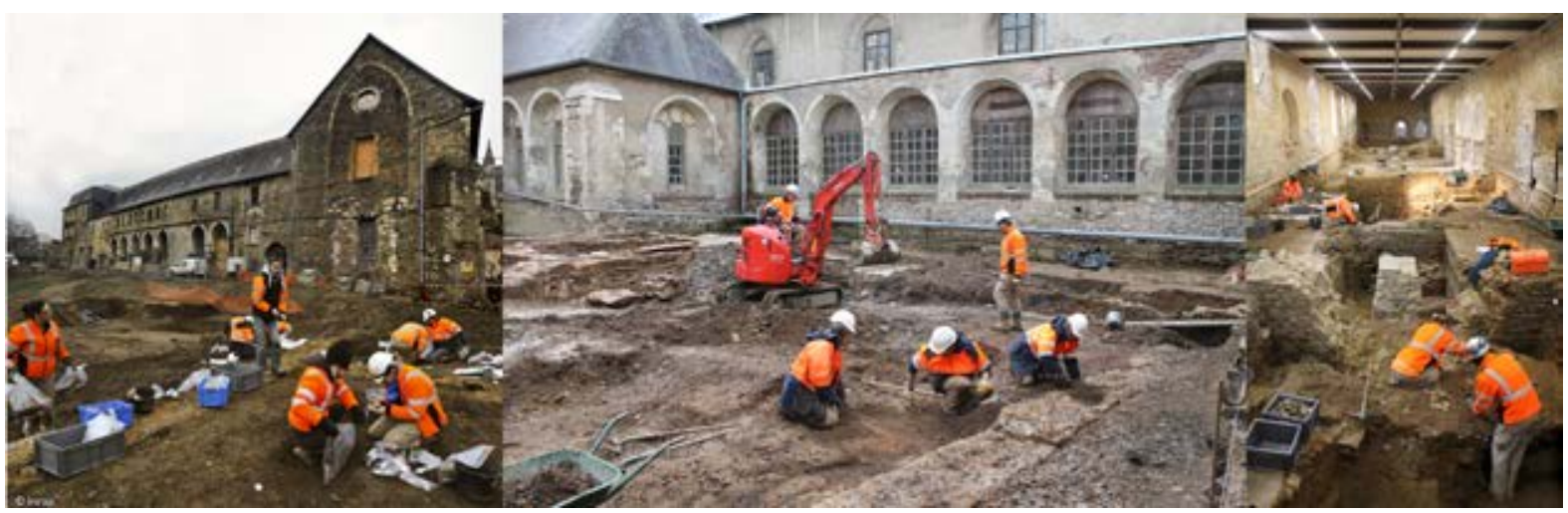

Fig. 2. Left: excavation at the west courtyard (๑ H. Paitier / Inrap), Center: excavation at the cloister garden (๑ G. Le Cloirec / Inrap), Right: excavation at the east wing (cl. H. Paitier / Inrap).

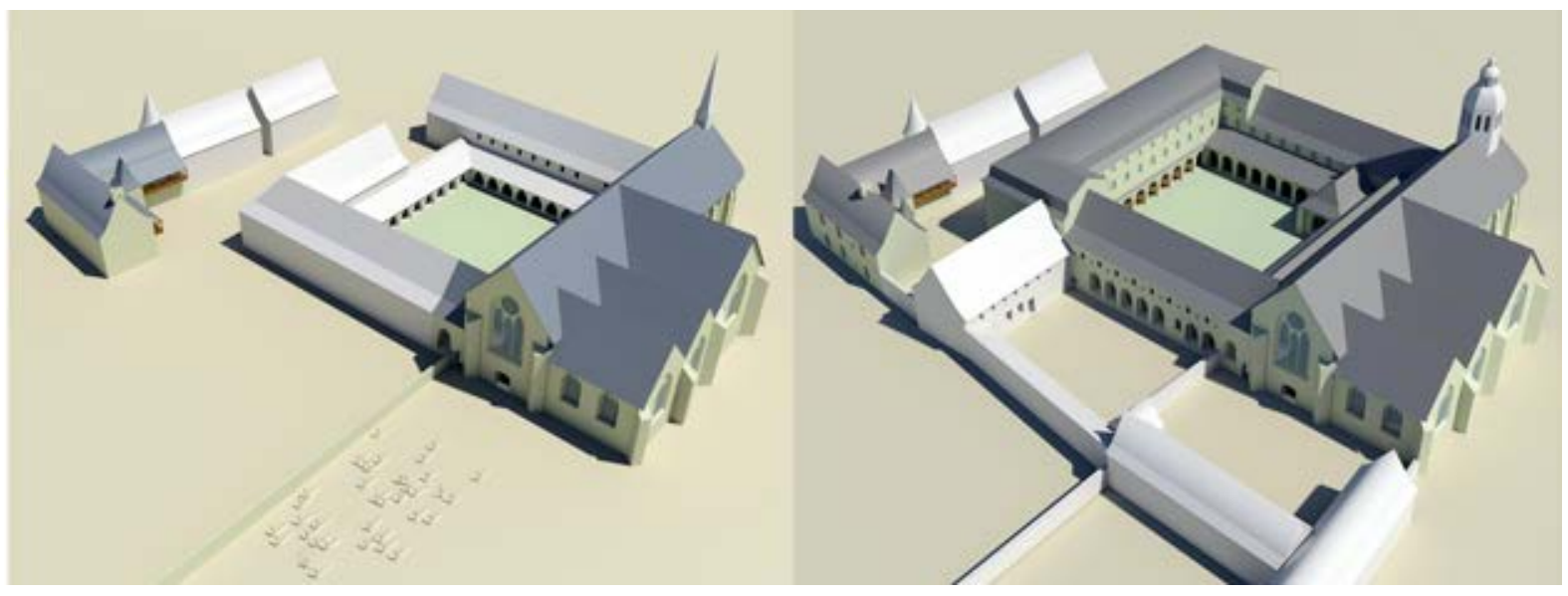

Fig. 3. Schematic organization of the convent in the 15th century (left) and 17th century (right) (3D G. Le Cloirec / Inrap).

The refectory, a place where the shale plate engraved was discovered, is the largest room in the convent measuring $28 \mathrm{~m}$ in length and $7.5 \mathrm{~m}$ in width (Fig. 4). Five successive soils were discovered during the excavation. The first three consisted of a single layer of clay while the last two were made of terracotta tiles. It is in the leveling embankment of the first pavement that the engraved tablet of a partition was found.

\subsection{Description of the tablet}

The tablet with the musical score is part of a set of a dozen pieces engraved with more or less complex patterns (Fig. 5). The material, a slate shale of local origin, is particularly suitable for engraving. From the early Middle Ages, these 10 to $20 \mathrm{~cm}$ wide slabs (litter size or slate roof) often served as a support to register ideas, accounts, make drawings or caricatures, and were sometimes transformed into a board game. The various dry point drawings were probably created with the help of a metal tool. Similar to a school slate, graffiti, sometimes made by different people, can then be superimposed over time on a single plate. 


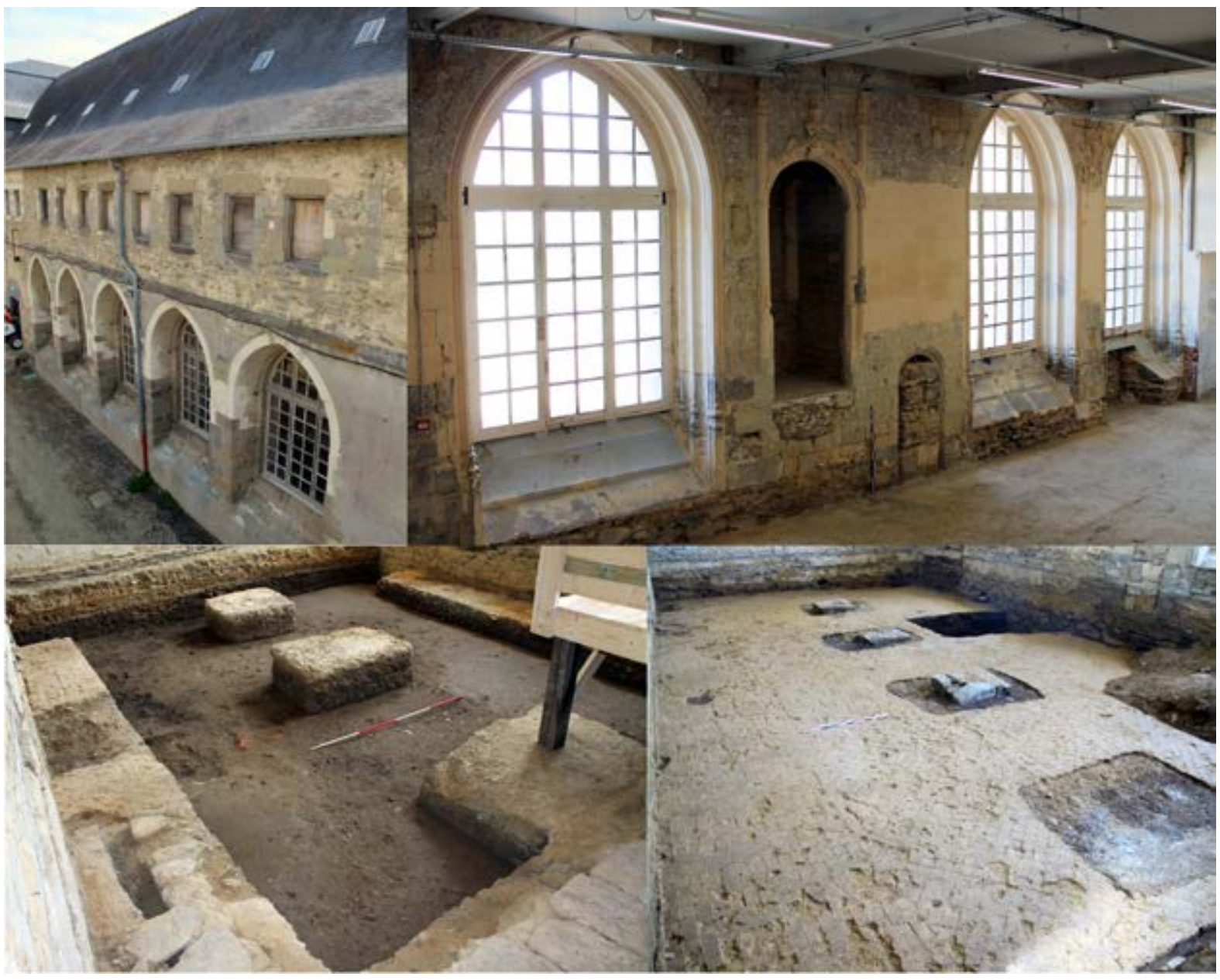

Fig. 4. Top, left: West facade of the convent integrating the windows of the refectory surmounted by openings that illuminated the cells of the monks (๑ T. Bethus / Inrap). Top, right: interior of the refectory facing the West wall with the large windows and the pulpit of the reader (๑ T. Bethus / Inrap). Bottom, left: first clay floor of the refectory (๑ T. Bethus / Inrap). Bottom, right: vestiges of the first floor of terracotta of which only the imprints remain in the laying mortar (๑ T. Bethus / Inrap).

2.2.1 The plate with the score. Made from a good quality shale plate, the slab is incomplete, with all the edges broken (size $17 \times 15 \times 0,5 \mathrm{~cm}$ ). It has graffiti on both sides (Fig. 6). On the first (Fig. 7, top), a musical score is superimposed on a wheel pattern with 11 spokes carrying a succession of ordered numbers on the circular part. The surface has several words or lines of identifiable writing, but clearly corresponding to different handwritings.

On the other side (Fig. 7, bottom), the main element consists of linear lines forming three nested squares, representing a very fashionable game in the Middle Ages known as Nine Men's Morris or Mill game. The lines of the game, certainly drawn first, served as a guide for the engraving of several letters and words, including large Gothic letters near the edge (Fig. 7, bottom). 


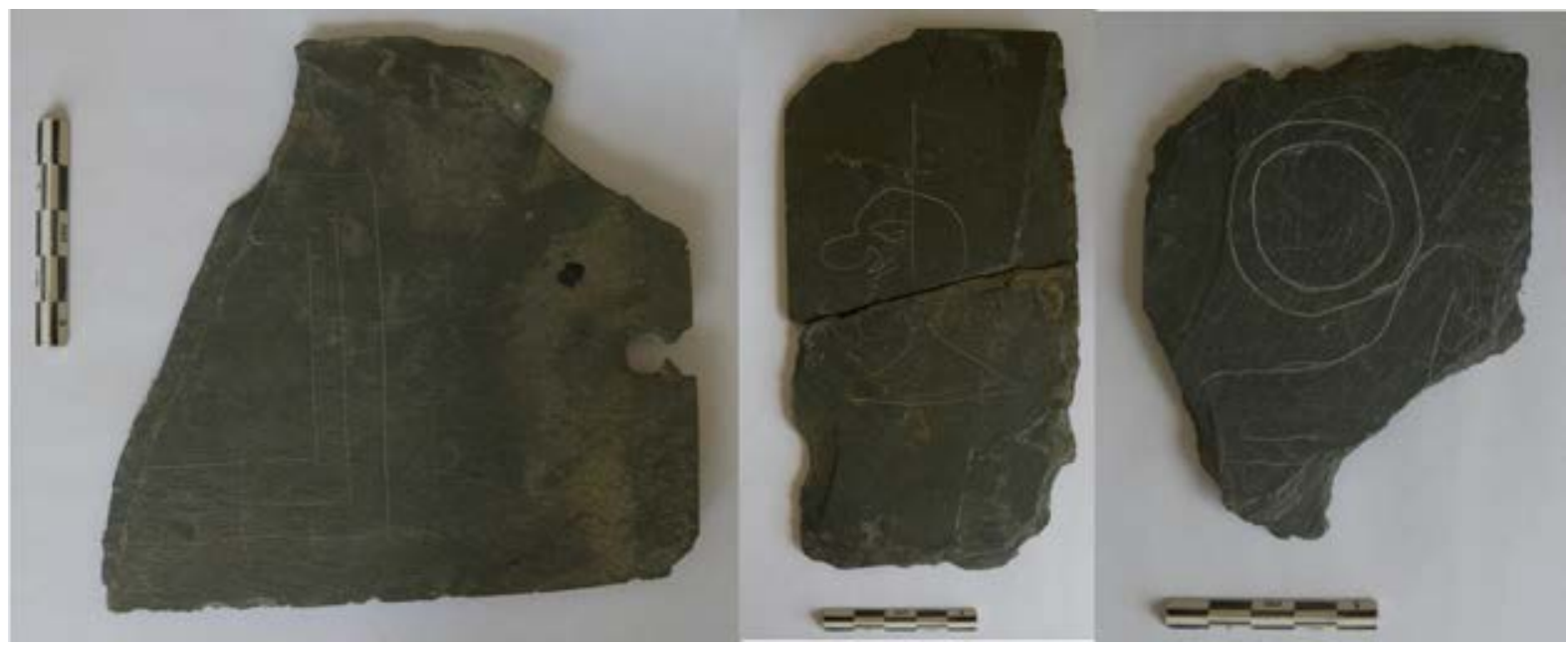

Fig. 5. Left: fragment of a roof slab with a Nine Men's Morris engraving (๑ F. Labaune-Jean / Inrap). Center: plate with a caricature of person's profile, perhaps a monk (৫ F. Labaune- S. Jean / Inrap). Right: plate with a drawing of a circle and a horse (๔ F. Labaune-S. Jean / Inrap).

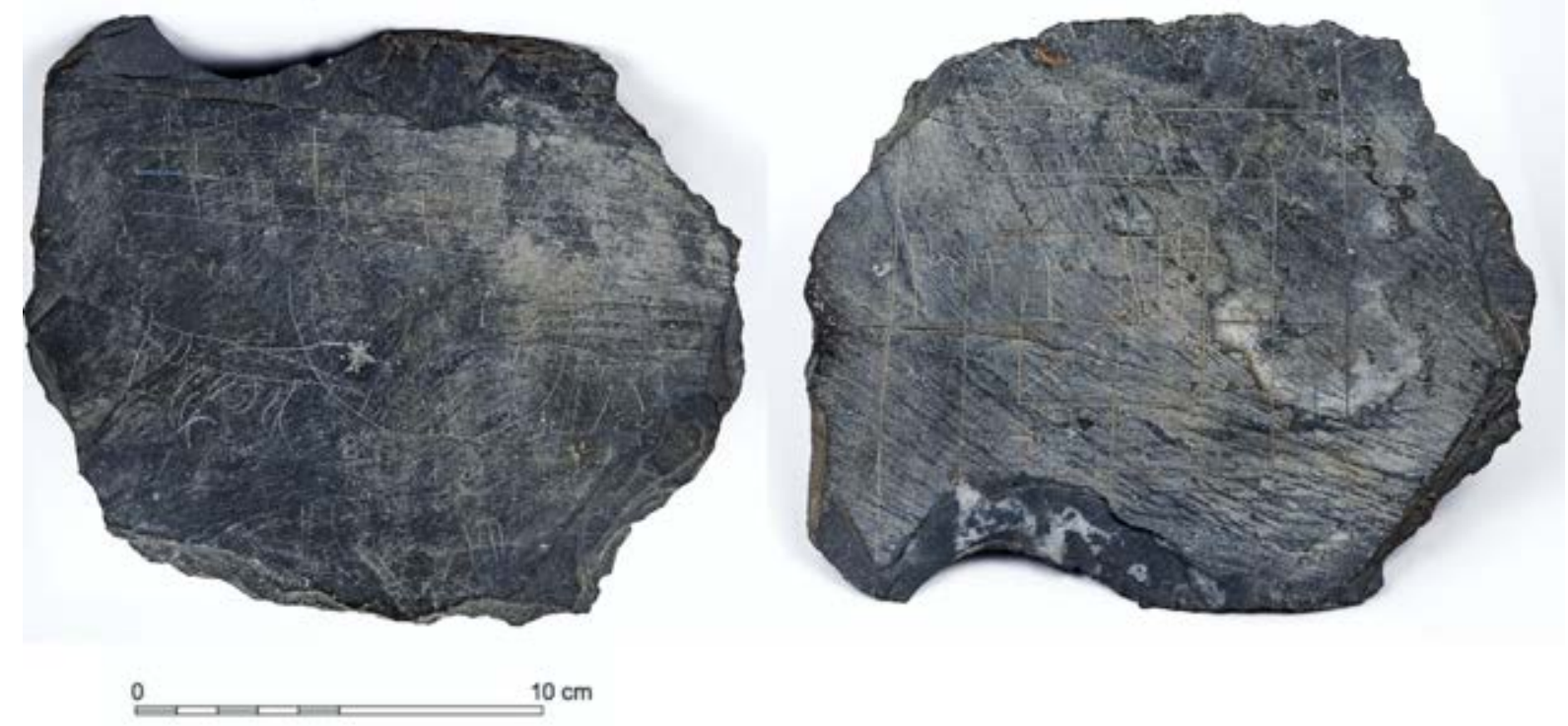

Fig. 6. The two sides of the tablet (๔ B. Arnaldi, Irisa).

2.2.2 The music score. The score engraved on the first side, and presented in Figure 8, is in the form of a musical stave with four lines on which a $\mathrm{C}$ key is visible on the third line, which means that the notes on the third line starting from the lower line will be $\mathrm{C}$ notes. The 39 notes, semi-brief, are diamond shape and without tail, which is not unusual for this period. They correspond to our current quarter notes and are all equal in duration. There 

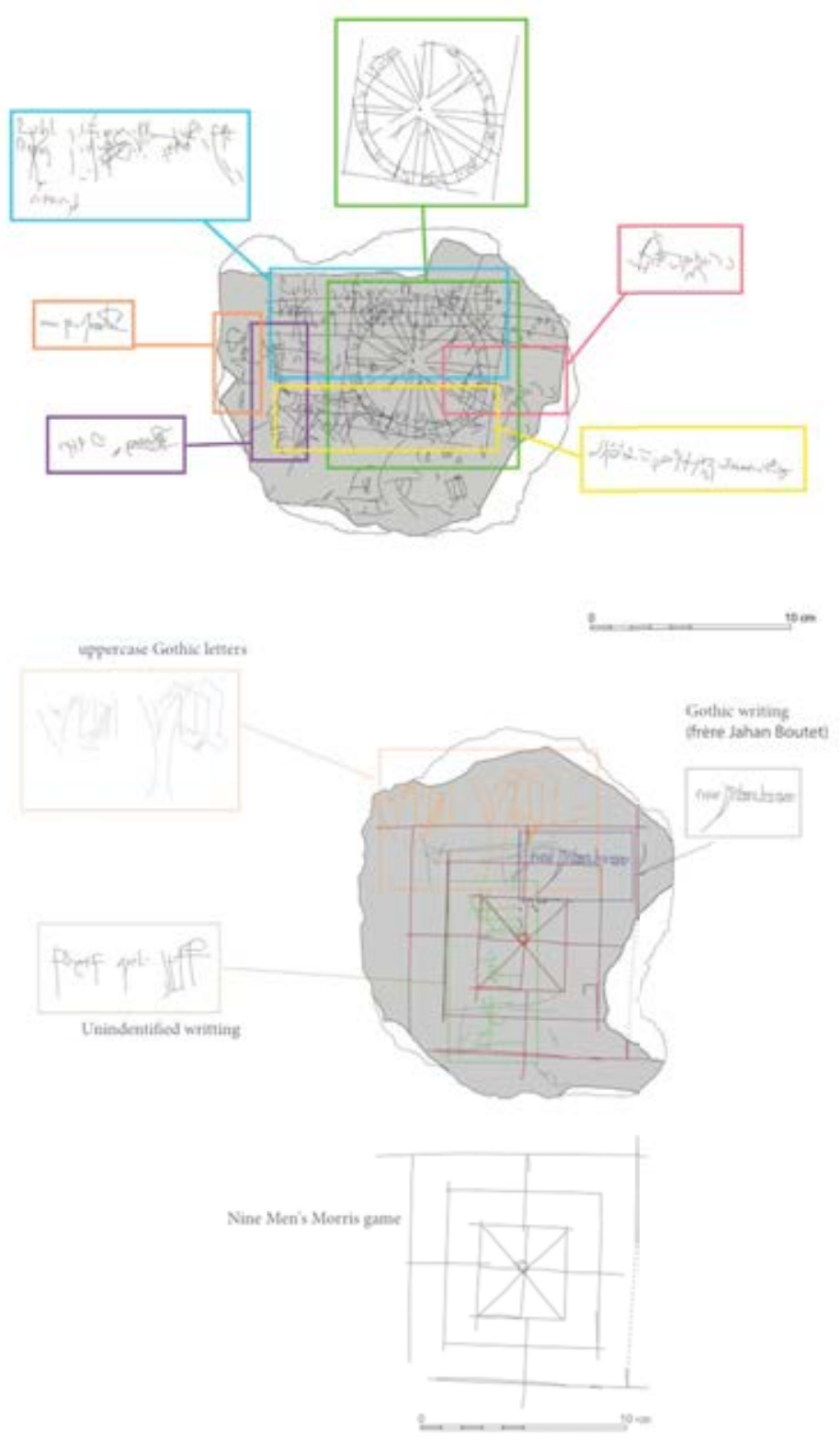

Fig. 7. Presentation of different graffiti on the first (top) and reverse (bottom) sides (๔ F. Labaune, S. Jean, Inrap).

is no silence and no text that would guide us to a known musical piece. We do not recognize a known Gregorian melodic formula. The mode, if we consider that the melody is complete, is a natural minor A or aeolian A mode, which does not really appear until the fifteenth century. Religious songs in this period were mainly in four modes: Dorian (D), Phrygian (E), Lydian(F), and Myxolydian (G). The ambitus would be perfect for a sharp, male tenor 

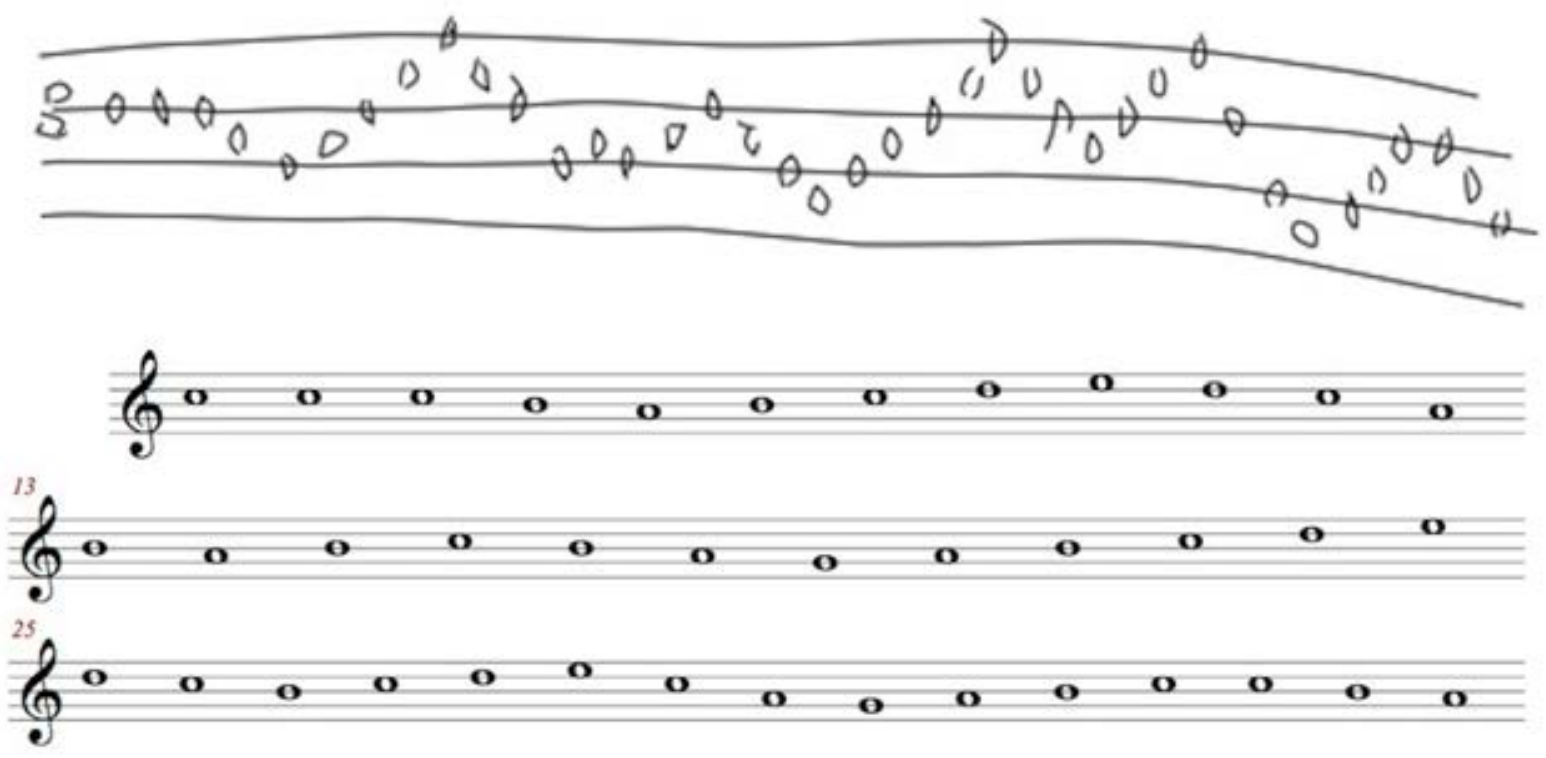

Fig. 8. Top: Transcription of the music score (@ D. Fontaine, F. Labaune-S. Jean, G. Le Cloirec / Inrap). Bottom: Transcription in modern musical notation, in the G key (transcription D. Fontaine).

voice. The musician who created the engraving did not sign it, which is not surprising. In the case of an original melody, the absence of a signature is common to many ancient and religious works for which the author, inspired by God himself, would not allow himself to appropriate the creation of what he sincerely believed was coming from heaven.

\section{DIGITIZATION PROCESS}

Among the several engraved tablets discovered during the excavation, it has been decided to digitize the engraved tablet with the music score because of the richness of the engraving on both sides, and because of the presence of the music score that is very particular. Three main motivations guided the choice of digitization, (i) the tablet is very fragile, (ii) digitization may help to better identify some graffiti, and (iii) the digital copy of the tablet would serve as a basis for an interactive valorization application of the tablet.

\subsection{Digitization techniques}

Three different techniques of digitization have been used for the tablet: standard photogrammetry, Reflectance Transformation Imaging, and digital microscopy.

3.1.1 Photogrammetry. Photogrammetry is a well-known technology of image data processing, that allows to produce metric and 3D data from a set of 2D point of views [Hallert 1960], [Mikhail et al. 2001]. It is widely used in the heritage domain for recording and documentation [Remondino 2011], [Guarnieri et al. 2010]. This technology has been used in particular for rock engravings [Mudge et al. 2012] where it is combined with Reflectance Transformation Imaging. 
3.1.2 Reflectance Transformation Imaging (RTI). Reflectance Transformation Imaging (RTI) is a technology developed in the early 2000s by the Cultural Heritage Imaging, a non-profit corporation dedicated to heritage preservation through the dissemination of new technologies (2017). It is a computational photographic method that captures a subject's surface shape and color from a series of frontal photographs under different artificial lighting and enables the interactive re-lighting of the subject from any direction [Malzbender et al. 2001]. This technology is particularly useful in the context of objects with light relief such as paintings [Aure et al. 2017]. It was thus well suited for the engraved tablet with its very thin carving.

3.1.3 Digital microscopy. A digital microscopy is a variation of a traditional optical microscopy that uses optics and a digital camera to output an image to a monitor, generally processed by a computer software. Current digital microscopy usually provides advanced processing features such as 3D reconstruction. This technology is already used in cultural heritage [Cacciari et al. 2014], [Moretti et al. 2015].

\subsection{Photogrammetry of the tablet}

We used a DSLR Canon 5DmkII, a 21.1-megapixel full-frame CMOS digital single-lens reflex camera, with a lens type Canon EF $85 \mathrm{~mm} \mathrm{f} / 1.8$ Macro USM. The studio was equipped with 2 flashes, Walimex PRO VC-300 with Softbox, to have a uniform lightening with minimal shadows. The object was presented on a white background, and placed on a turntable. The capture was performed in two passes: first with one side up, and second with reverse side up, to achieve complete coverage of the object. For each pass, the camera was oriented at three different angles with respect to the horizontal. For the first pass, we took 43 photos, and for the second pass, 48 photos. The raw pictures were transformed into jpeg format, with a resolution of $5086 \times 3391 \mathrm{px}$, using Lightroom 5.7, to increase contrast, clarity, and sharpness. We used Agisoft PhotoScan Standard Edition to align the photos and generate a point cloud. For the capture, the software was able to align the totality of the photos. For the first series, we obtained 5168 tie points for alignment, a dense cloud of 8.7 million points (ultra-high quality), and a mesh with 1.7 million faces. For the second series, we obtained 6129 tie points, a dense cloud of 9.2 million points (ultra-high quality), and a mesh with 1.8 million faces. The meshes were cleaned and aligned with Meshlab, blender and CloudCompare. The resulting mesh for the tablet has 967.000 faces (Figure 9).

\subsection{Reflectance Transformation Imaging (RTI)}

We built our own RTI system mostly from the the specification presented in [7], except for the dome for which a plastic salad bowl was used, with matte black paint on the inside. The dome has a diameter of $34 \mathrm{~cm}$, and was drilled with 60 holes filled with white leds (Fig. 10).

We used a Canon EOS 6D, a 20.2-megapixel full-frame CMOS digital single-lens reflex camera, with a lens type Canon EF16-35mm f/4L IS USM. The 60 raw pictures, one per led lighting, were transformed into jpeg, with a resolution of $5472 \times 3648 \mathrm{px}$, using the Lightroom 5.7 software, and we used RTI builder 2.0.2, with Hemispherical Harmonics (HSH) fitting algorithm to generate RTI data (Fig. 11, left). We used 2 black marbles from an abalone game as reflective spheres. RTI data was used to produce a precise normal map (Fig. 11, right) of 3361x3193 px in order to be used in the interactive application for dynamic lightening.

\subsection{Digital microscopy}

In order to obtain more precise data for particularly illegible graffiti, we performed digital microscopy with a Keyence VHX 5000 system, equipped with a VH-Z20T Universal Zoom Lens 20x to 200x (Fig. 12, left). With respect to optical data, this system enables features to measure, highlight and agglomerate data on large areas (Fig. 13), and allows for the generation of 3D digital data (Fig. 12, right). The microscopy was operated by a physicist in the presence of two archaeologists who were in charge of the study of the tablet. 


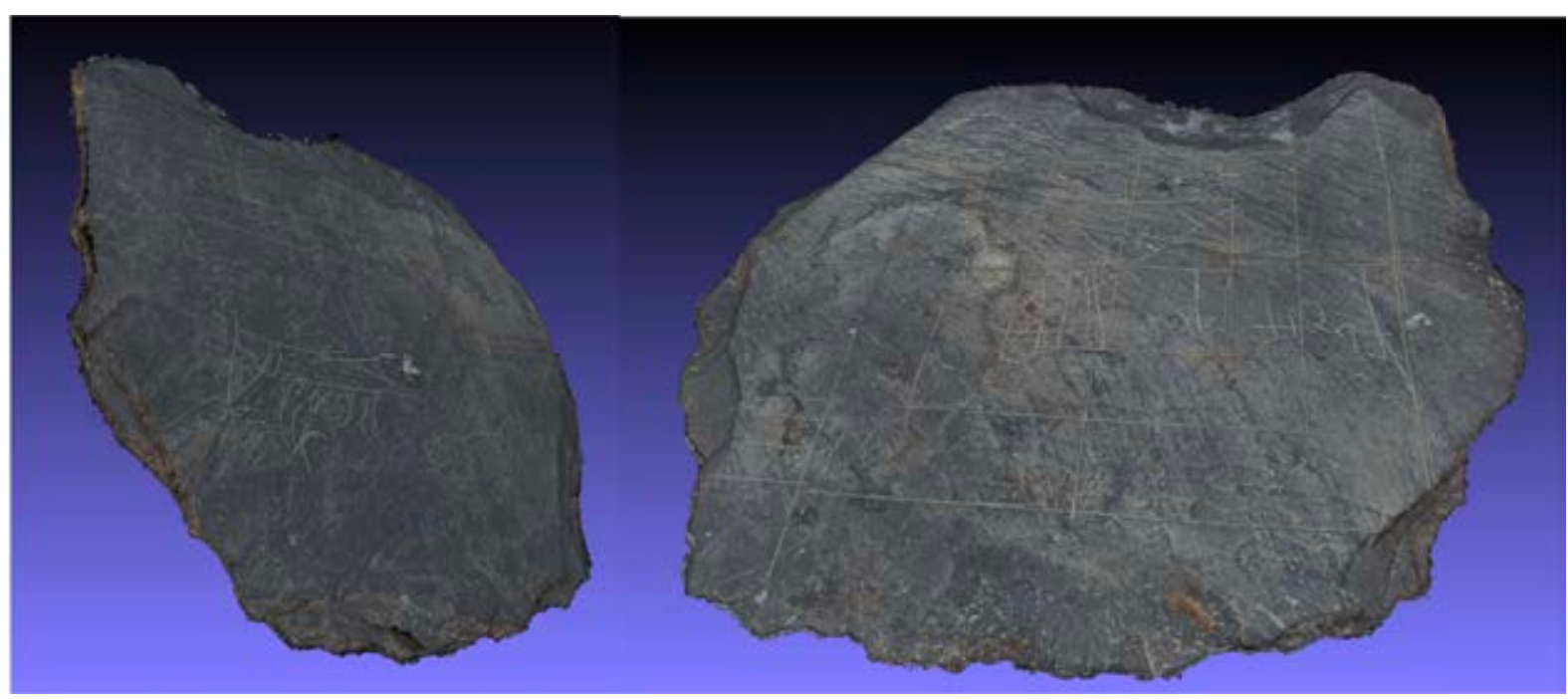

Fig. 9. 3D model of the tablet.

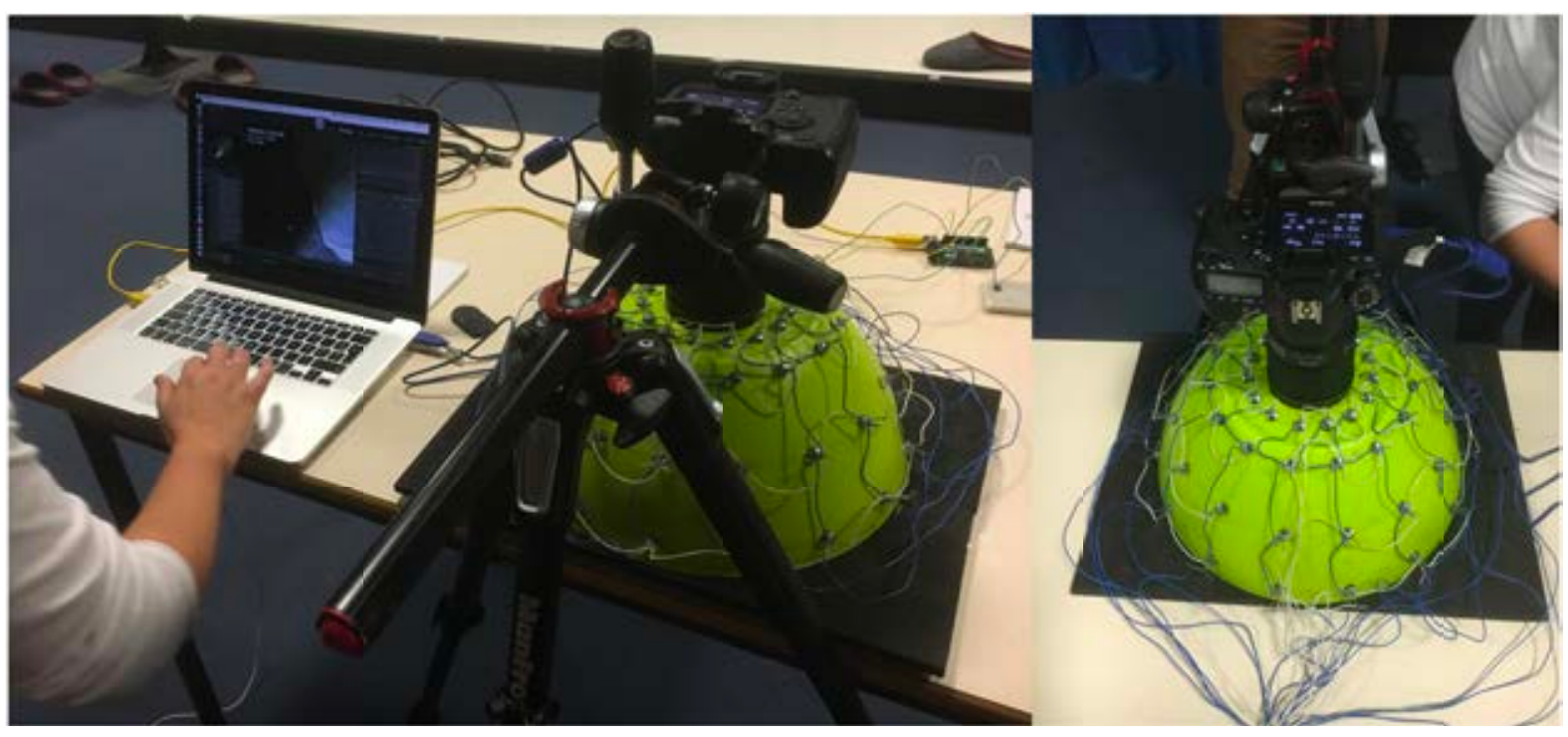

Fig. 10. Digitization of the tablet with the RTI dome.

\subsection{Analysis of digital data}

Digital data from photogrammetry and RTI is mainly used for the interactive 3D applications. The photogrammetry setup used in the project was not accurate enough to generate a mesh representing the thin engravings. In figure 14 , on a close view of the mesh around the score, only the main traces such as the lines of the score are visible. The thinner traces are rendered through the texture. In comparison, the normal map generated from the RTI capture, as presented in figure 15, provides more details on engravings than the same area presented in figure 14. 


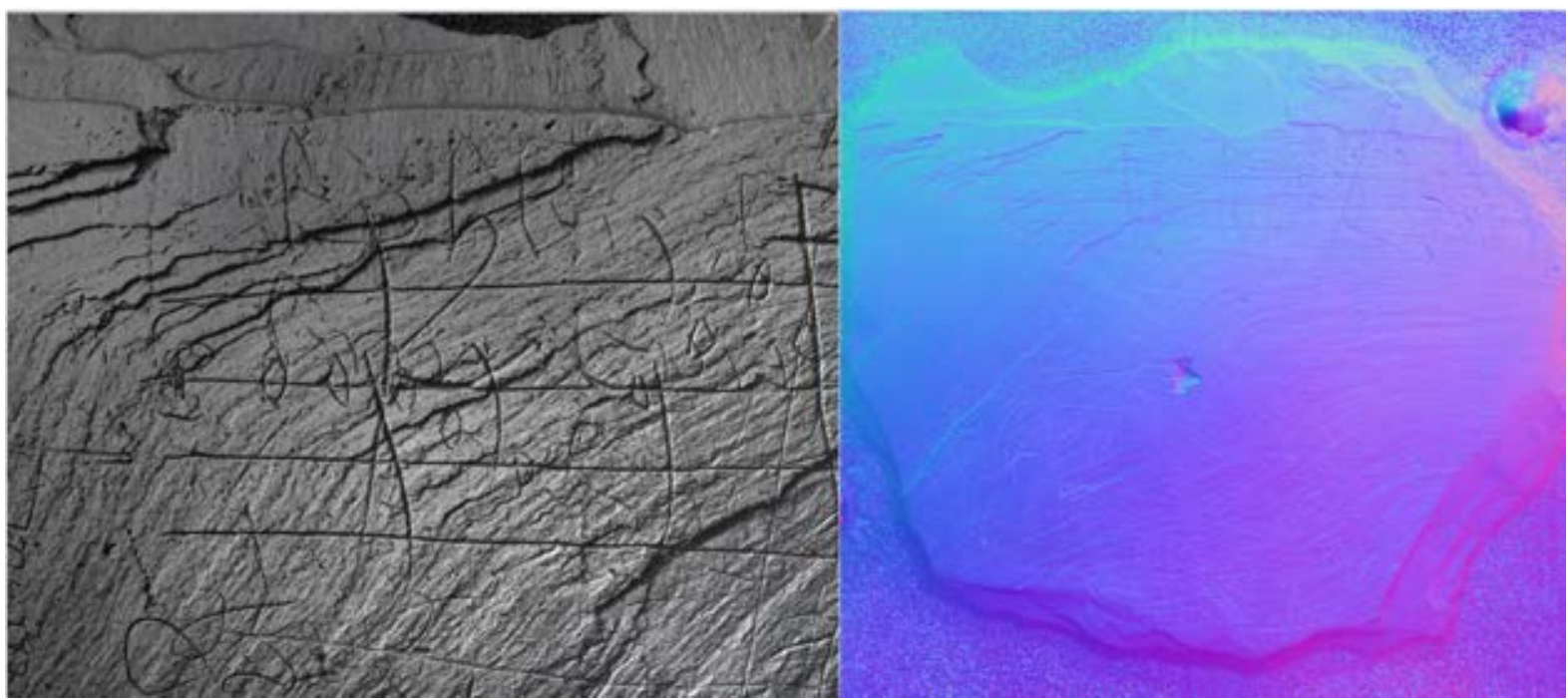

Fig. 11. Specular rendering from RTI builder (left) and normal map (right).

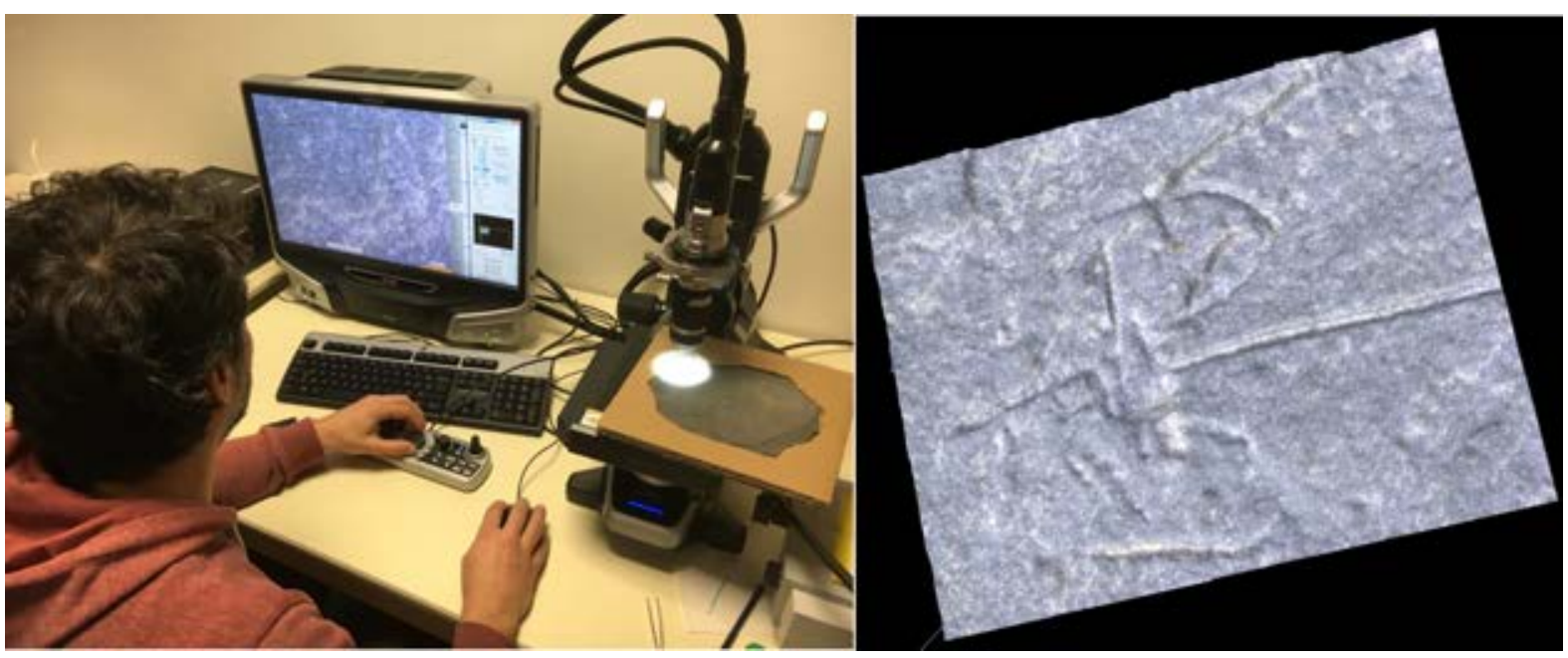

Fig. 12. Left: Digital microscopy on the tablet. Right: 3D rendering of the $\mathrm{C}$ key.

Digital microscopy was used to explore hypotheses on the writings. In particular, one question was raised on the existence of lyrics on top of the music score, and digital microscopy could provide the answer to this question. The structure of the beginning of the score, magnified by the digital microscope, is presented in figure 16. In the red rectangle, two connected circles over a line represent a $C$ score. In the green rectangle, the diamond shapes on and between the lines represent the music notes. In the blue rectangle above the lines, some writings were proposed as potential lyrics for the score. This was not confirmed as the microscope revealed that some 


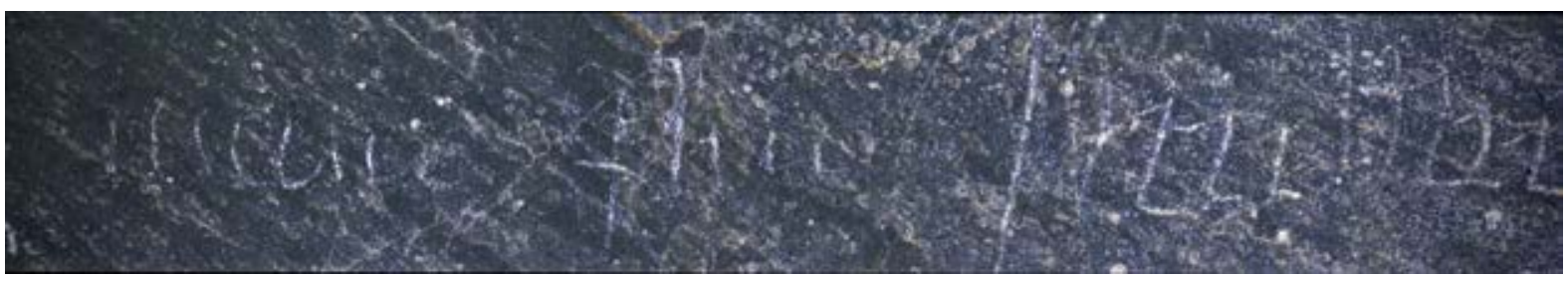

Fig. 13. Reconstructed rendering of a graffiti.

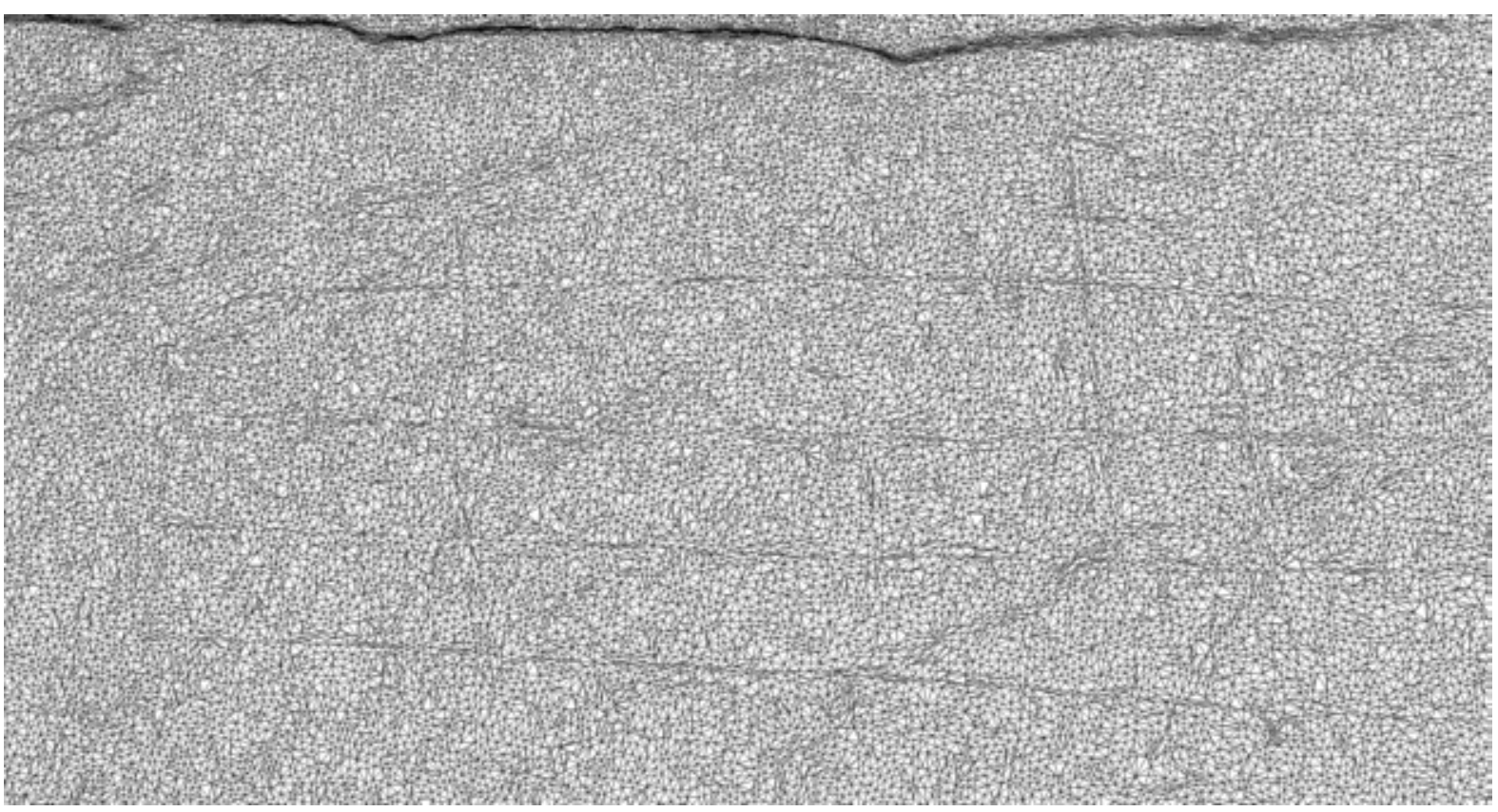

Fig. 14. Detailed view of the mesh, with the four lines of the score.

characters were engraved prior to the score lines and some were engraved posterior, as shown in figure 17 where the two red rectangles illustrate two different anteriorities of two letters with respect to the upper score line.

\section{INTERACTIVE APPLICATION}

An interactive application was developed in order to present the results of the study of the tablet to a wide audience. We targeted an interactive application on tactile tablet to propose intuitive multi-touch interactions. The 3D model of the tablet displayed in the application is the one generated with the photogrammetry. The main functionalities of the application are highlighted visualisation of the graffiti, free manipulation of the 3D tablet, manipulation of a light source, interaction with the musical score, and access to pages of explanations on the object and its discovery. 


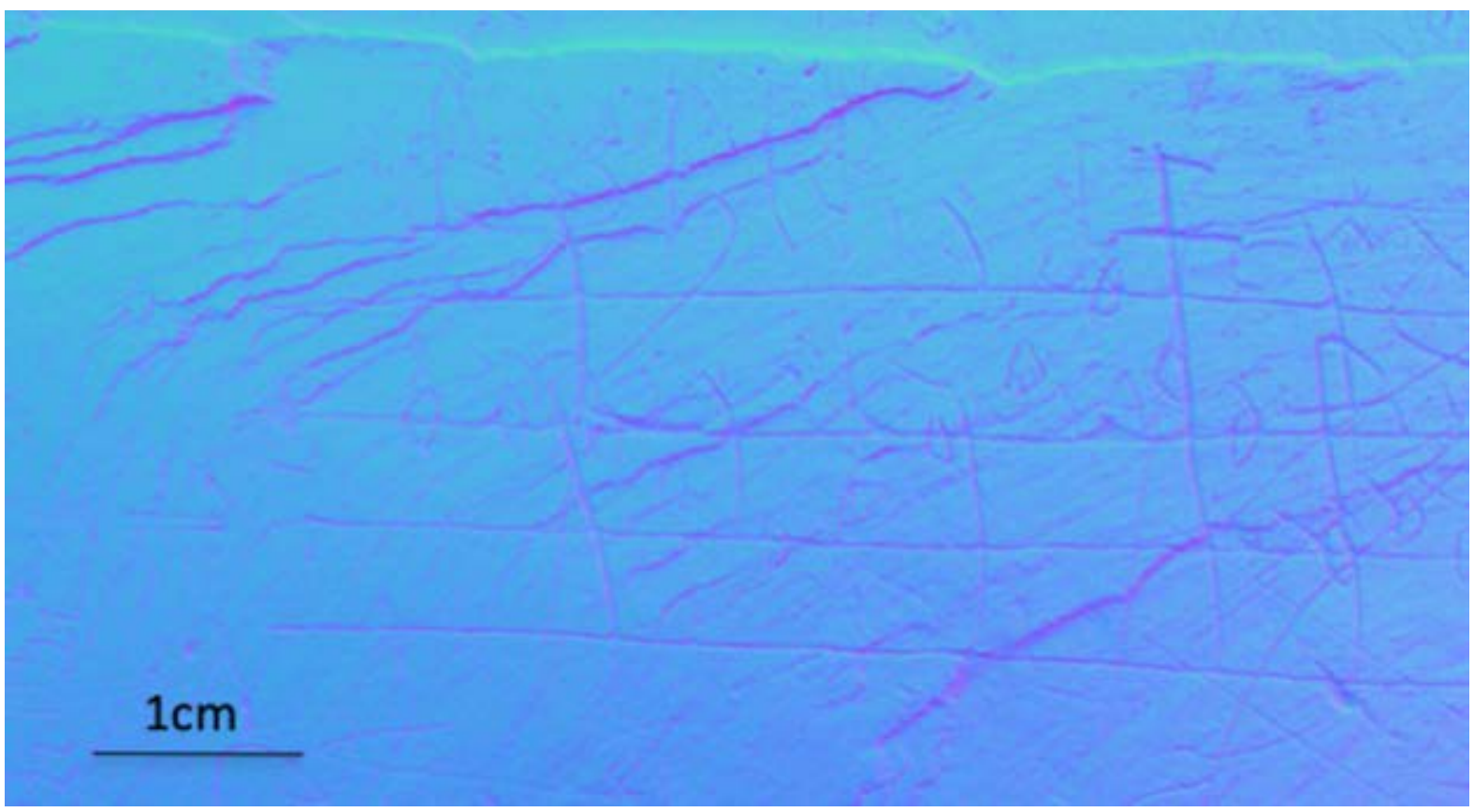

Fig. 15. Detailed view of the normal map, for the same area as shown in figure 14 .

\subsection{Interaction with the tablet}

The goal of this interaction is to allow the user to manipulate the 3D model of the tablet as naturally as possible in order to visualize both side, and detailed parts of the graffiti. The graffiti on the tablet are highlighted with clickable colored boxes (Fig. 18, top), and an explanation and visualization of the selected graffiti are displayed when the area his touched by the user (Fig. 18, bottom). The different graffiti can also be browsed and displayed through arrows icons at the bottom of the screen. The colored boxes can be hidden for a better visualization of the whole engraved tablet, and standard multi-touch interactions allow to manipulate it: orbital rotation with one finger, planar rotation by rotating one finger around one fixed finger, zoom in/out by bringing two fingers closer/further apart, translation by sliding two fingers.

\subsection{Interaction with the light}

The goal of this interaction is to highlight the reliefs of the tablet and the engravings. The control of the light is activated with the light icon at the bottom, left of the screen. When activated, an active area is displayed in the upper right corner of the screen (Fig. 19, top, right), with a slider to control the intensity of the light, and a representation of the point light position with respect to tablet, which can be moved with one finger. The light rendering is based on the data generated with the RTI digitization.

\subsection{Interaction with the music}

The goal of this interaction is to allow the user to experience the music engraved on the tablet either by playing it or by listening to a prerecorded song of the music. When the musical score area is activated, either through the colored box, or through the area browser, an active graffiti of the score is displayed, with all the notes playable 


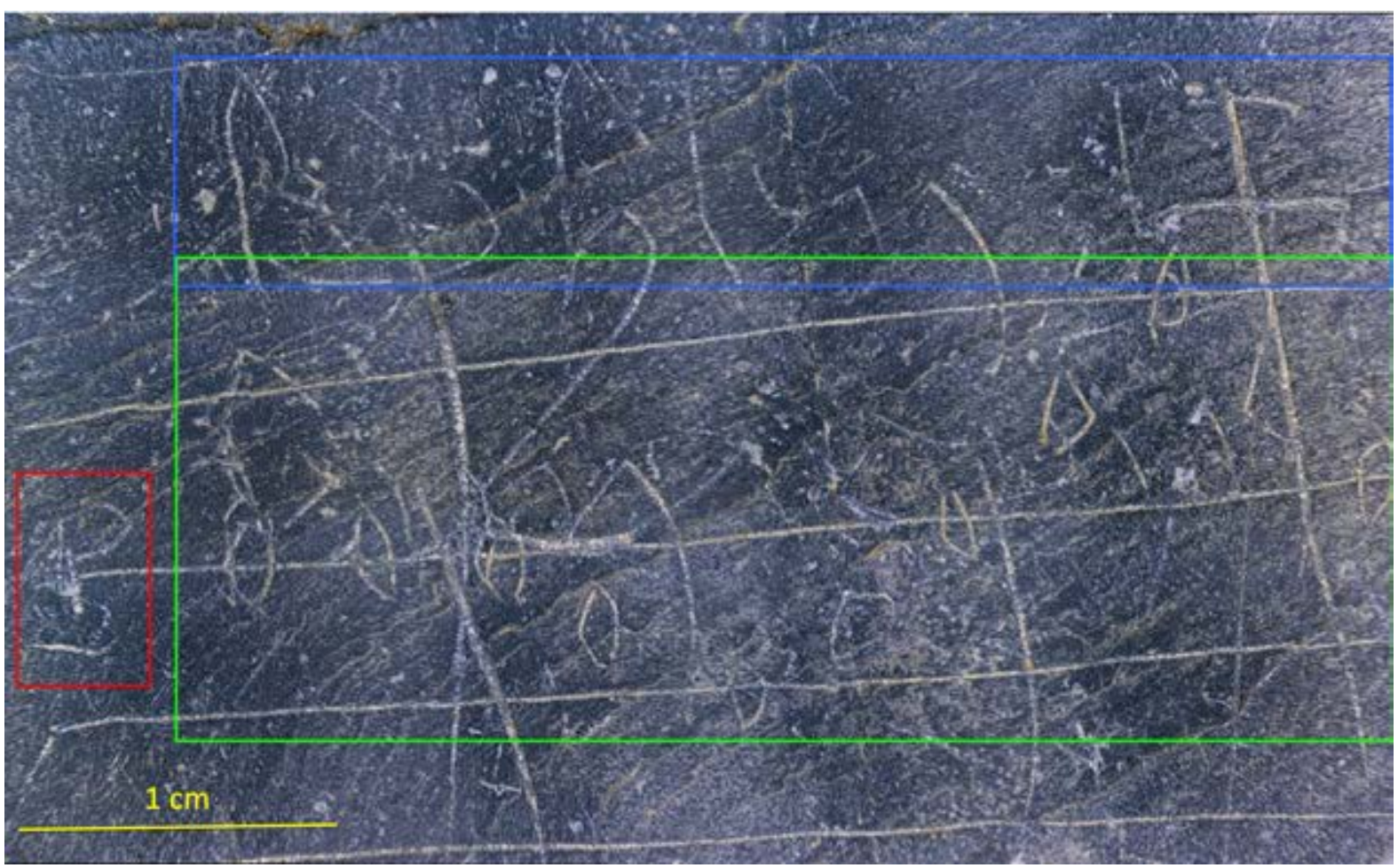

Fig. 16. Structure of the score area.

(Fig. 20). When a note is touched, it is highlighted with a colour (Fig. 20, right) and the corresponding sound is produced, either with a piano sound or a voice sound, depending on the mode selected in the lower right corner of the explanation box. A play icon allows to launch an interpretation of the score sung by Dominique Fontaine. A cursor follows the song on the score in order to indicate the note currently played to the user (Fig. 20, left).

\subsection{Display of explanations}

The goal of this interaction is to present the context of the discovery to the user. An "Information" icon opens a succession of 8 pages that displays pictures and explanations (in French) about the context of the discovery (Figure 21). The pages are browsed with back and forward arrows icons, and a "Home" icon allows the user to come back to the interactive application.

\subsection{Implementation}

The application was implemented with the game development platform Unity 3D, and deployed as a PC standalone executable on a Microsoft Surface Pro 4 and a HP ElitePad 1000 tablet. A WebGL version was also generated from Unity to be on the Web.

\section{EXHIBITION}

The original tablet was presented together with the two digital tablets to the "science and music day" (http://jsm.irisa.fr), in October 2017, organised by the computer science research laboratory. The form of the presentation was a 


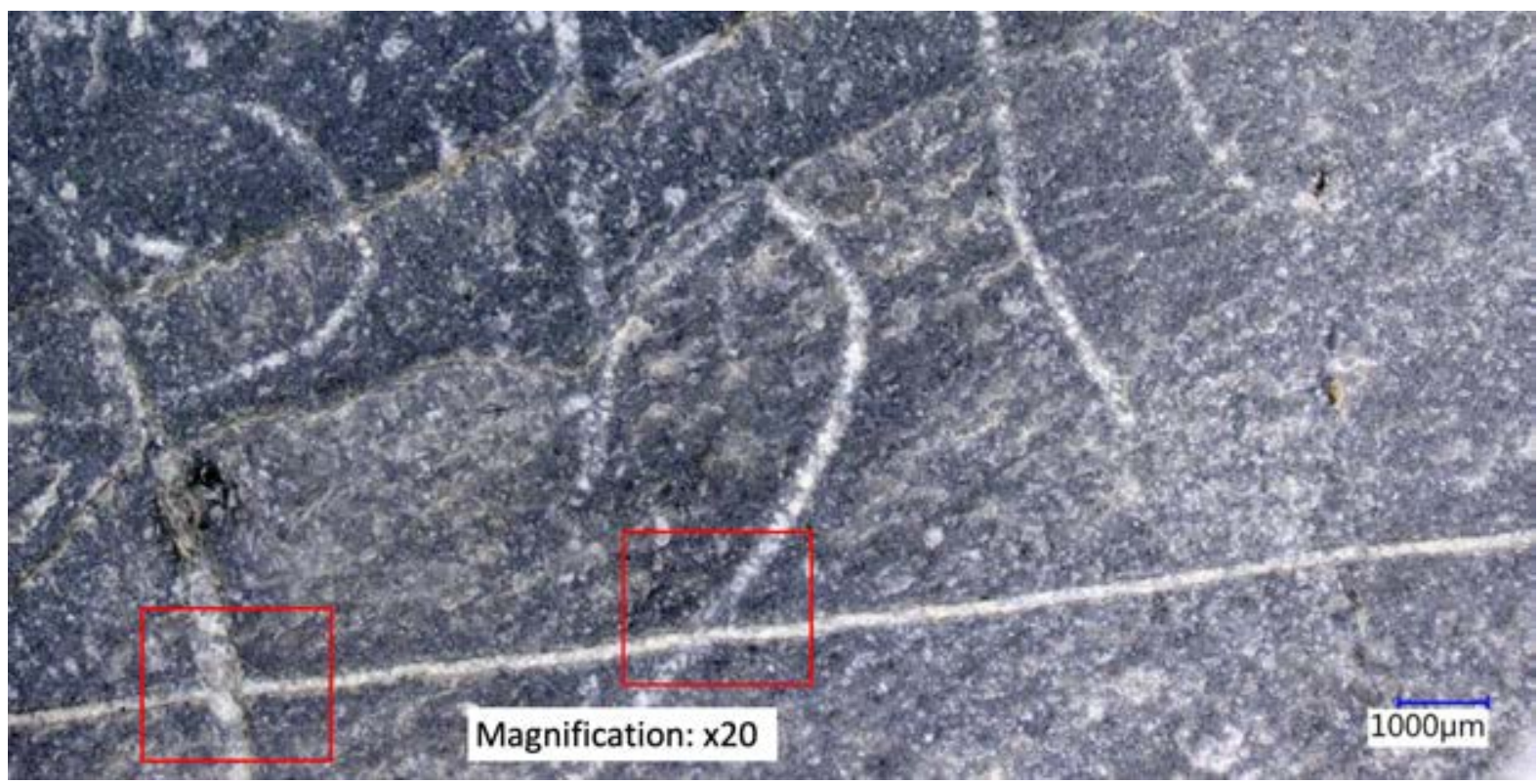

Fig. 17. Details on the writings above the score.

workshop of 30 minutes, repeated throughout the afternoon for groups of 20 people (Fig. 22). The presentation had four parts: first, the archaeologists presented the archaeological context of the discovery of the tablet. Second, Dominique Fontaine presented the score in its historical context and performed a live interpretation. After the score, the computer scientists presented the digitization process and implementation of the interactive application, and finally, by interacting with the public, both the real and the virtual tablet were presented (Fig. 22, bottom). A total of about 150 visitors followed the presentation during the day. A new exhibition of these two versions of the tablet was performed in June 2019, in a Museum context.

\section{DISCUSSION}

The project illustrates the use of several digital technologies on an archaeological object, with three main and distinct goals:

- Preserve a fragile artifact. The stone of the tablet is very fragile, and engravings are subject to erosion and erasure. It is thus important to put in place preservation measures, and digitization provides interesting complementary properties with respect to traditional physical protection measures. In particular, digital data is easily replicable and sharable. The different digitization techniques used on the tablet allowed to perform a detailed recording of the object and to extrapolate different properties which highlight the content of the tablet.

- Contribute to the analysis of the artifact. Engravings on the tablet overlap each other, and some inscriptions are barely legible. RTI digitization and digital microscopy enabled a better vizualisation of the graffiti and testing of the proposed hypotheses. In particular, digital data allowed to confirm the presence of the $\mathrm{C}$ key which was not obvious in the first studies. It also invalidated a hypothesis about the presence of lyrics for the score. Indeed, some delicate engravings detected with optical binoculars close to the notes 


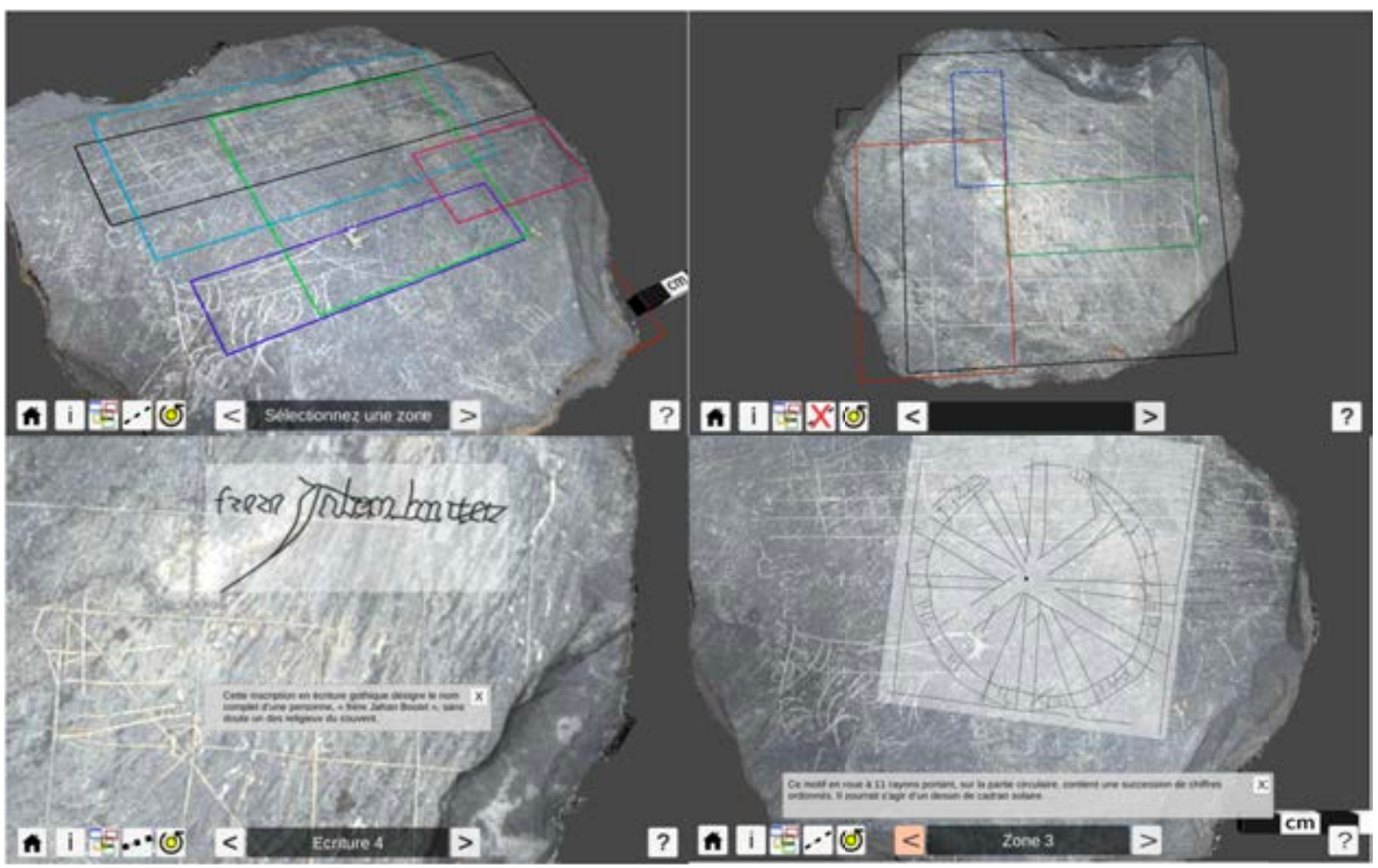

Fig. 18. The interactive tablet. Top: 3D views of both sides of the tablet with different graffiti highlights. Bottom: visualization of a particular area of one inscription (left) and of the wheel pattern (right).

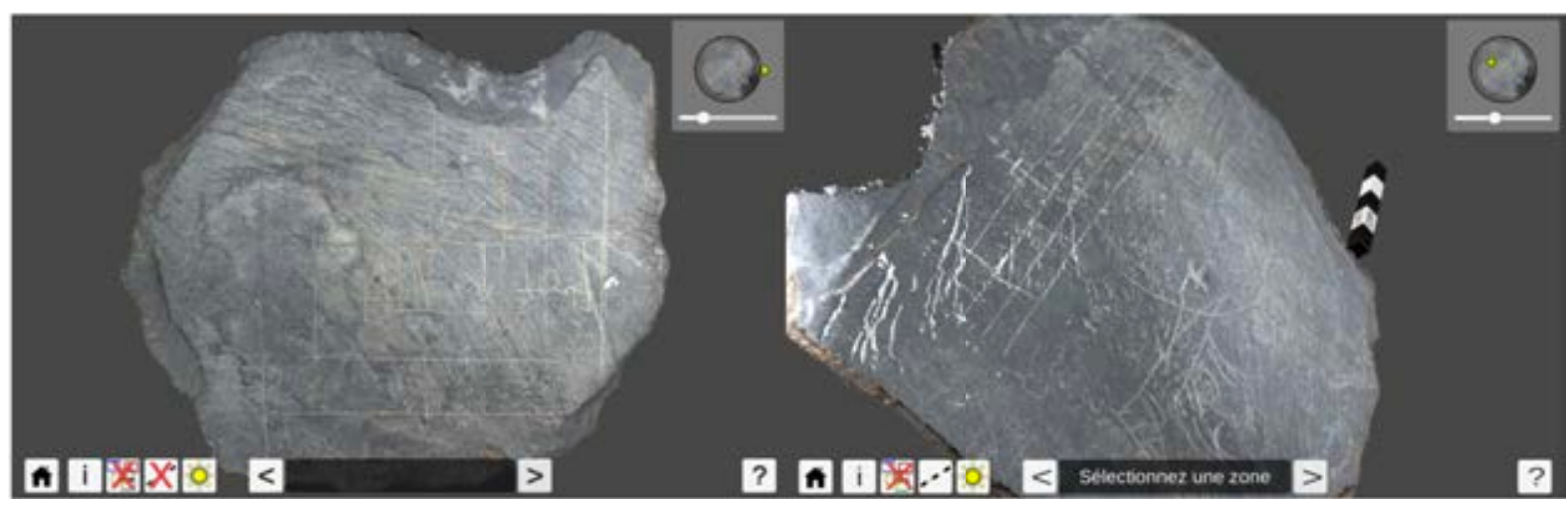

Fig. 19. Interactive manipulation of the light. The user can change the position and intensity of the light source with the interface in the upper right corner.

could have been interpreted as initials of words. RTI and digital microscopy did not confirm this hypothesis, and digital microscopy indicated that the anteriority of these writings were different. 


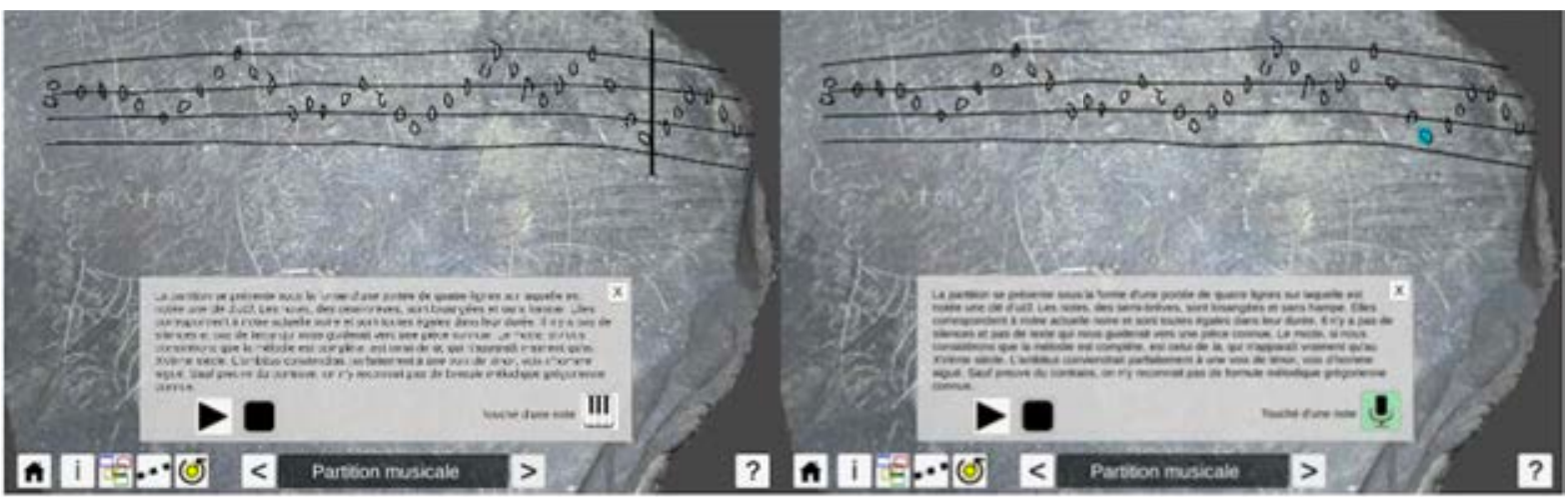

Fig. 20. The interactive musical score.

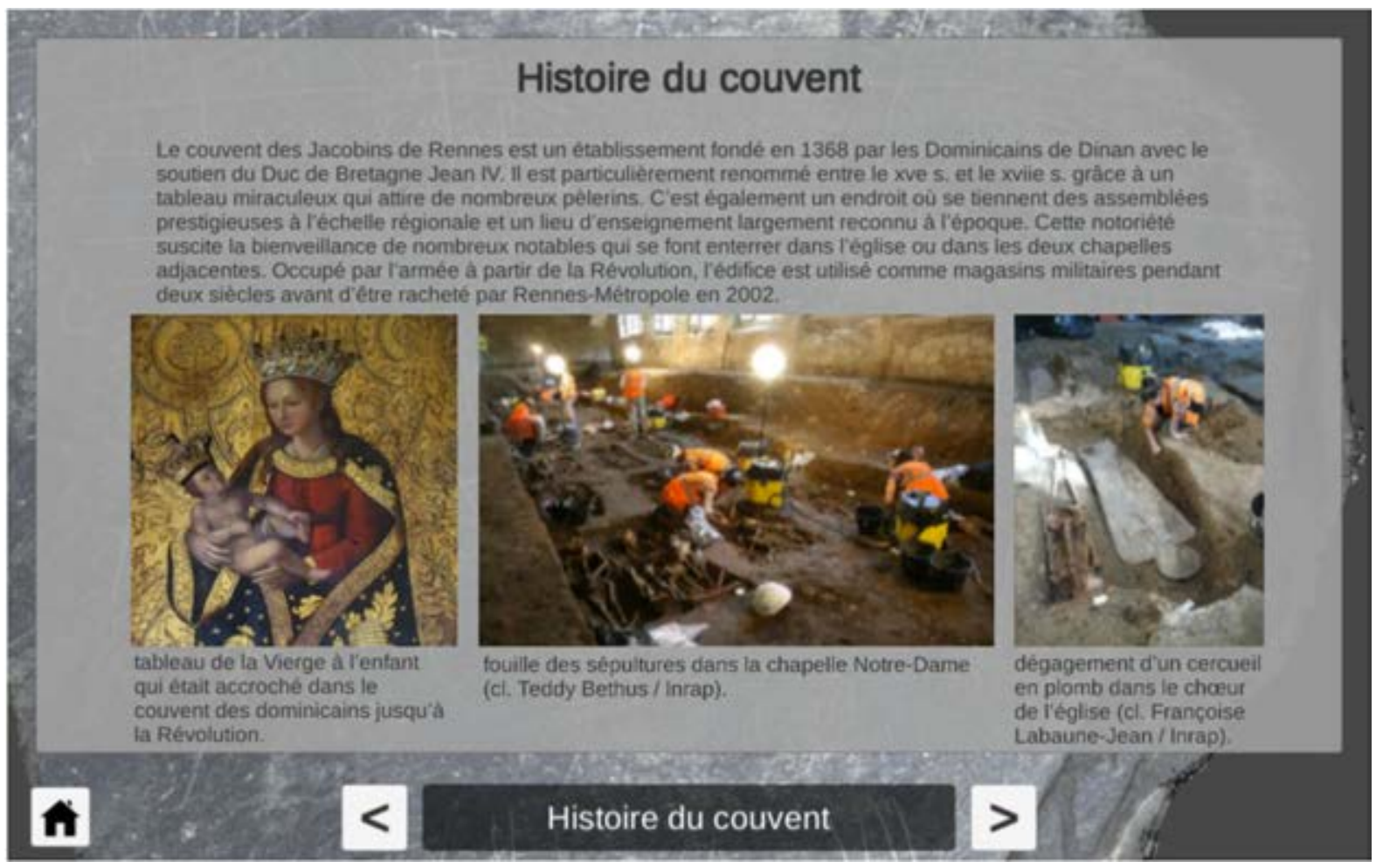

Fig. 21. Presentation of the historical context of the discovery within the interactive application.

- Valorize an artifact that embeds intangible heritage. The engraved tablets represent an uncommon testimony of the everyday life in a 15th century Covent. In particular, the musical score gives access to an intangible form of heritage that was valorized in that project through an interactive application on a tactile tablet. This application, based on the 3D data obtained from the digitization of the tablet, combined 


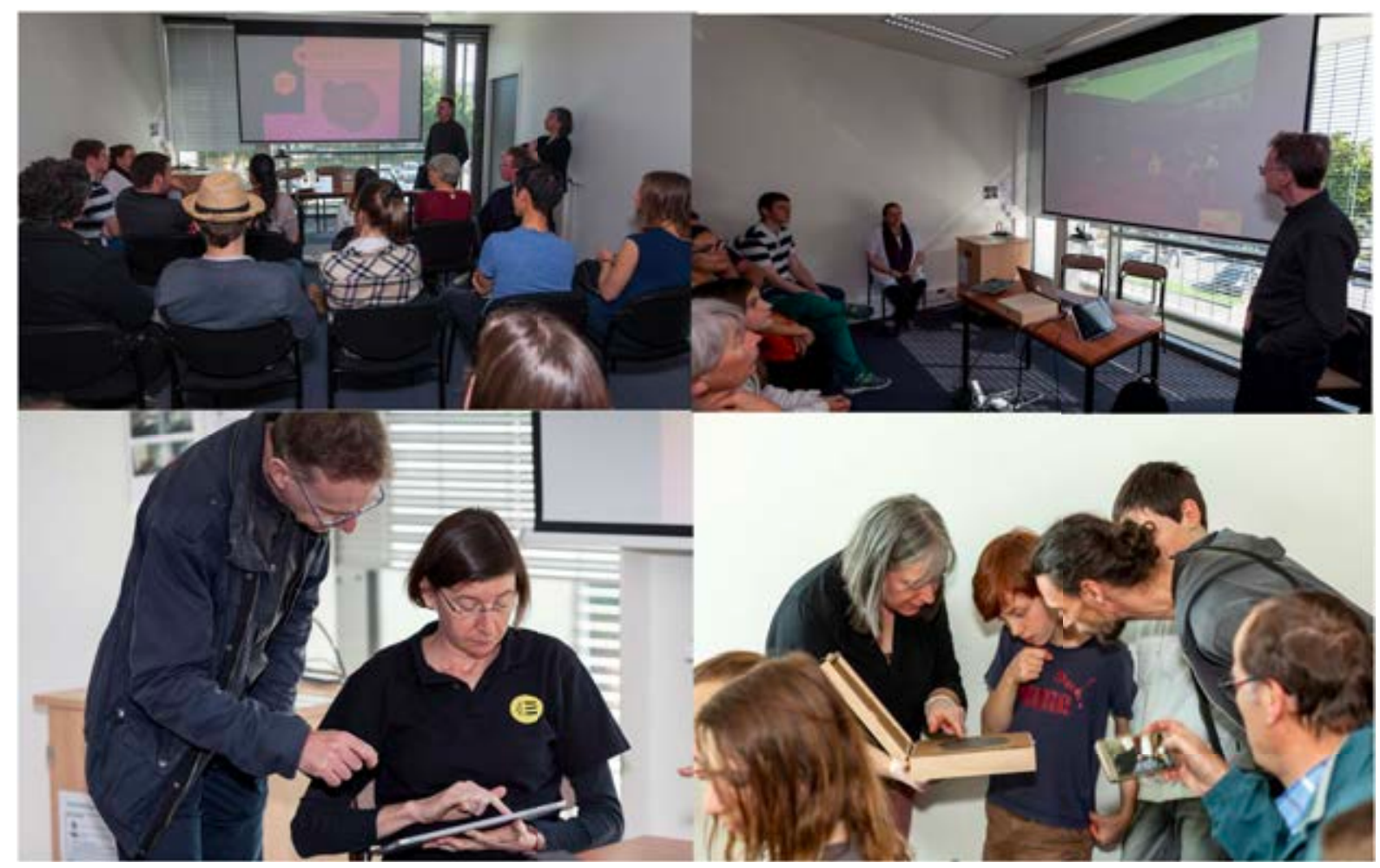

Fig. 22. Presentation of the tablet to the public. Top: Presentation conference given by the full team involved in the work. Bottom, left: The interactive tablet. Bottom, right: The original tablet.

with a record of an interpretation of the score, and a presentation of the analysis of the engravings by archaeologists, creates a comprehensive medium to share the discovery with the public. The application is currently only available on Windows and Android tablets and should be deployed to other tablets through Unity. The adaptation of the application to WebGL could be used for broadcasting it on websites and to reach a wider audience.

When dealing with digital data, the question of their durability and preservation must be also handled. The first aspect is the sustainability of the digital medium. In order to have as little dependency to the medium as possible, we chose to store our data on two different NAS systems of our research institutes. The second aspect is the sustainability of the data format. This is related to the ability to access the data through a software. In order to maximize the sustainable accessibility to our data and its interoperability, we kept the raw data of the photos, and two widespread standard formats of images (png and jpeg). The sustainability of the transformed data, such as RTI data or the interactive application, are much more difficult to guarantee. Nevertheless, the transformations of the original data and the implementations on top of the transformed data are reproducible, given the initial digital data.

\section{CONCLUSIONS}

The 15th century engraved tablet studied in this manuscript was discovered during preventive archaeological excavations, with about ten other engraved tablets. The presence of a musical score among the engraved 
inscriptions motivated the digitization of the tablet in order to preserve this fragile artefact, and to help the analysis of the inscriptions. The digitization used photogrammetry to produce a textured 3D model of the tablet, RTI to produce a precise normal map, and 3D digital microscopy to produce a magnification of certain parts of the engravings. The resulting 3D model was used to produce an interactive tactile application on digital tablets that was presented at the science mediation events. The application integrates a musical interpretation of the score performed by a professional singer specialized in Renaissance music. A web version of the application is also proposed to present the results to a wider audience. This work is an interesting example of the value of using 3D digital technology for the preservation, analysis and sharing of an archaeological artefact, and in particular, the valorization of intangible heritage.

\section{AUTHOR CONTRIBUTIONS}

Ronan Gaugne led the digitization processes and the implementation of the interactive tablet. Françoise Labaune was the archaeologists in charge of the study of the tablet. Dominique Fontaine performed the study of the musical score and the musical interpretation. Gaétan Le Cloirec was the archaeologist responsible for the excavation of the site. He was the lead researcher of the archaeological study. Valérie Gouranton was the lead researcher of the digital study of the tablet. She is also the coordinator of the INTROSPECT ANR-FRQ-SC project.

\section{ACKNOWLEDGMENTS}

This work was partially funded by the ANR-16-FRQSC-0004 INTROSPECT project. The authors whish to thank Quentin Petit, engineer at Inria, and Pierre-Nicolas Eudes, student at INSA Rennes, for their work on digitization and implementation, Bruno Arnaldi, professor at INSA Rennes, for taking the pictures for the photogrammetry, Isabelle Puault, Professor at University of Rennes 1, for taking the pictures for the RTI, Fabrice Célarié, associate professor at University of Rennes 1, for operating the digital microscopy, and Florian Nouviale, research engineer at INSA Rennes, and Ewen Camberlein, engineer at Inria for recording and producing the interpretation by Dominique Fontaine of the music score.

\section{REFERENCES}

anonymous. 2012. Renaissance score engraved in church's exterior. Peregrinations: fournal of Medieval Art and Architecture 3, 3 (2012). https://digital.kenyon.edu/perejournal/vol3/iss3/18/

Atrium Musicæ de Madrid and Gregorio Paniagua. 1979. Musique de la Grèce Antique. CD recording, Harmonia Mundi "musique d'abord" HMA 1951015.

Xavier Aure, Paul O’Dowd, and Joseph Padfield. 2017. Generating 3D Models of Paintings through the Combination of 2D, 3D and RTI Data. In Proceedings of the Conference on Electronic Visualisation and the Arts (London, United Kingdom) (EVA '17). BCS Learning Development Ltd., Swindon, GBR, 25-32. https://doi.org/10.14236/ewic/EVA2017.4

Howard Mayer Brown and Louise K Stein. 1999. Music in the Renaissance. Pearson College Division.

Ilaria Cacciari, Pierluigi Nieri, and Salvatore Siano. 2014. 3D digital microscopy for characterizing punchworks on medieval panel paintings. Journal on Computing and Cultural Heritage ( $7 O C C H)$ 7, 4 (2014), 1-15.

Franco de Colonia, Gilbert Reaney, and André Gilles. 1974. Ars cantus mensurabilis. American Institute of Musicology Rome.

Marcelle Duchesne-Guillemin. 1980. Sur la restitution de la musique hourrite. Revue de musicologie (1980), 5-26.

Ensemble De Organographia, Gayle Stuwe Neuman, and Philip Neuman. 2006. Music of the Ancient Sumerians, Egyptians Greeks, new expanded edition. CD recording, Pandourion Records PRDC 1005.

Alberto Guarnieri, Francesco Pirotti, and Antonio Vettore. 2010. Cultural heritage interactive 3D models on the web: An approach using open source and free software. fournal of Cultural Heritage - J CULT HERIT 11 (07 2010), 350-353. https://doi.org/10.1016/j.culher.2009.11.011 Bertil Hallert. 1960. Photogrammetry, basic principles and general survey. (1960).

Josh Jones. 2017. Renaissance Knives Had Music Engraved on the Blades; Now Hear the Songs Performed by Modern Singers. (2017). http://www.openculture.com/2017/07/renaissance-knives-had-music-engraved-on-the-blades-now-hear-the-music-performedby-modern-singers.html

Gaétan Le Cloirec. 2014. Rennes (Ille-et-Vilaine). Le couvent des Jacobins. Archéologie médiévale 44 (2014), $236-237$.

Werner Lemberg. 2016. A survey of the history of musical notation. TUGboat 37, 3 (2016), $284--304$. 
Tom Malzbender, Dan Gelb, and Hans Wolters. 2001. Polynomial texture maps. In Proceedings of the 28th annual ACM Siggraph conference on Computer graphics and interactive techniques. 519-528.

Edward M Mikhail, James S Bethel, and J Chris McGlone. 2001. Introduction to modern photogrammetry. Wiley, New York, NY, USA.

Erika Moretti, Simona Arrighi, Francesco Boschin, Jacopo Crezzini, Daniele Aureli, and Annamaria Ronchitelli. 2015. Using 3D Microscopy to Analyze Experimental Cut Marks on Animal Bones Produced with Different Stone Tools. Ethnobiology Letters 6 (12 2015), 50. https://doi.org/10.14237/ebl.6.2.2015.349

Mark Mudge, Carla Schroer, Tommy Noble, Neffra Matthews, Szymon Rusinkiewicz, and Corey Toler-Franklin. 2012. Robust and scientifically reliable rock art documentation from digital photographs. A companion to rock art (2012), 644-659.

Gustave Reese. 1959. Music in the Renaissance. WW Norton New York.

Fabio Remondino. 2011. Heritage recording and 3D modeling with photogrammetry and 3D scanning. Remote sensing 3, 6 (2011), $1104-1138$.

Jon Solomon. 1986. The Seikilos inscription: a theoretical analysis. The American fournal of Philology 107, 4 (1986), 455-479.

Martin Litchfield West. 1994. The Babylonian musical notation and the Hurrian melodic texts. Music \& letters 75, 2 (1994), 161-179.

Reginald Pepys Winnington-Ingram. 1929. Ancient Greek Music: A Survey. Music \& Letters 10, 4 (1929), 326-345.

\section{A ONLINE RESOURCES}

The webgl implementation of the application is available with this link: http://www.irisa.fr/immersia/tablettejacobins/ 